\title{
Septal contributions to olfactory bulb interneuron diversity in the embryonic mouse telencephalon: role of the homeobox gene Gsx2
}

Shenyue Qin ${ }^{1,2}$, Stephanie M. Ware ${ }^{5}$, Ronald R. Waclaw ${ }^{1,4}$ and Kenneth Campbell ${ }^{1,3^{*}}$ (D)

\begin{abstract}
Background: Olfactory bulb $(\mathrm{OB})$ interneurons are known to represent diverse neuronal subtypes, which are thought to originate from a number of telencephalic regions including the embryonic dorsal lateral ganglionic eminence (dLGE) and septum. These cells migrate rostrally toward the $O B$, where they then radially migrate to populate different $\mathrm{OB}$ layers including the granule cell layer (GCL) and the outer glomerular layer (GL). Although previous studies have attempted to investigate regional contributions to OB interneuron diversity, few genetic tools have been used to address this question at embryonic time points when the earliest populations are specified.

Methods: In this study, we utilized Zic3-lacZ and Gsxze-CIE transgenic mice as genetic fate-mapping tools to study $O B$ interneuron contributions derived from septum and LGE, respectively. Moreover, to address the regional (i.e. septal) requirements of the homeobox gene Gsx2 for OB interneuron diversity, we conditionally inactivated Gsx2 in the septum, leaving it largely intact in the dLGE, by recombining the Gsx2 floxed allele using Olig2 ${ }^{\text {Cre/t+ }}$ mice.

Results: Our fate mapping studies demonstrated that the dLGE and septum gave rise to OB interneuron subtypes differently. Notably, the embryonic septum was found to give rise largely to the calretinin ${ }^{+}\left(C R^{+}\right) \mathrm{GL}$ subtype, while the dLGE was more diverse, generating all major GL subpopulations as well as many GCL interneurons. Moreover, GsX2 conditional mutants (CKOs), with septum but not dLGE recombination, showed impaired generation of $\mathrm{CR}^{+}$ interneurons within the OB GL. These Gsx2 cKOs exhibited reduced proliferation within the septal subventricular zone (SVZ), which correlated well with the reduced number of $\mathrm{CR}^{+}$interneurons observed.

Conclusions: Our findings indicate that the septum and LGE contribute differently to OB interneuron diversity. While the dLGE provides a wide range of $O B$ interneuron subtypes, the septum is more restricted in its contribution to the $\mathrm{CR}^{+}$subtype. GsX2 is required in septal progenitors for the correct expansion of SVZ progenitors specified toward the $\mathrm{CR}^{+}$subtype. Finally, the septum has been suggested to be the exclusive source of $\mathrm{CR}^{+}$interneurons in postnatal studies. Our results here demonstrate that dLGE progenitors in the embryo also contribute to this $O B$ neuronal subtype.
\end{abstract}

Keywords: Neurogenesis, Neuronal specification, Olfactory bulb, Septum, Transcription factor

\footnotetext{
* Correspondence: kenneth.campbell@cchmc.org

'Divisions of Developmental Biology, Cincinnati Children's Hospital Medical

Center, University of Cincinnati College of Medicine, Cincinnati, $\mathrm{OH} 45229$,

USA

${ }^{3}$ Neurosurgery, Cincinnati Children's Hospital Medical Center, University of

Cincinnati College of Medicine, Cincinnati, OH 45229, USA

Full list of author information is available at the end of the article
} 


\section{Background}

Olfactory bulb (OB) interneurons represent a highly diverse neuronal population that serve as important components in the relay of olfactory signals from the environment to the brain [1]. They are largely inhibitory and modulate local projection neuron activity by releasing gamma-aminobutyric acid (GABA) [2, 3]. The complex functions of $\mathrm{OB}$ interneurons are accomplished by their high diversity, which, at least in part, can be recognized as subtypes based on distinct biochemical markers being expressed $[3,4]$. In addition, OB interneurons occupy distinct layers of the $\mathrm{OB}$, allowing them to exert their functions through building connections selectively with tufted cells or mitral cells, the major projection neurons in the $\mathrm{OB}[5,6,7]$. Interestingly, $\mathrm{OB}$ interneurons of different subtypes show varied preferences in layer localization and neuronal connectivity [3]. For example, tyrosine hydroxylase-labeled $\left(\mathrm{TH}^{+}\right)$ dopaminergic interneurons and calbindin ${ }^{+}\left(\mathrm{CB}^{+}\right)$interneurons are enriched in the glomerular layer (GL), whereas calretinin ${ }^{+}\left(\mathrm{CR}^{+}\right)$interneurons are found in both GL and granule cell layer (GCL). The specific roles of the diverse $\mathrm{OB}$ interneuron subtypes in olfactory circuits is not well defined, however, studies have shown these interneurons originate from the embryonic ventral telencephalon and regional progenitor domains in the postnatal SVZ $[2,8,9,10]$.

Unlike the locally born projection neurons [11, 12, 13], $\mathrm{OB}$ interneurons are generated caudal to the bulb within the ventral telencephalon, largely the lateral ganglionic eminence (LGE) and septum, from embryonic day 12 (E12) until birth and subsequently from the postnatal and adult SVZ, which represents the derivative of these embryonic germinal zones $[8,14,15,16]$. The newly specified neuroblasts migrate tangentially along the rostral migratory stream (RMS) to the OB, where they radially migrate to populate different layers and undergo maturation $[17,18]$. Recently, it has been suggested that $O B$ interneurons of distinct subtypes are produced by progenitor cells in different topological domains of the perinatal telencephalon $[2,7,9,10,16]$. For example, $\mathrm{TH}^{+}$interneurons were shown to be generated from the LGE, whereas $\mathrm{CR}^{+}$interneurons are suggested to be predominantly produced by the septum $[9,10,16]$. Despite the relatively detailed studies of the origins of OB interneuron subtypes, few genetic approaches have been taken to address the contributions of different progenitor domains to $\mathrm{OB}$ interneuron diversity at embryonic stages.

The normal generation and specification of $\mathrm{OB}$ interneurons are regulated by a number of transcription factors [7, 19]. For example, previous studies suggested that zinc finger transcription factor $\mathrm{Sp} 8$, which is expressed by many post-mitotic neuroblasts from both
LGE and septum, is essential for the normal generation of $\mathrm{CR}^{+}$and parvalbumin ${ }^{+} \mathrm{OB}$ interneurons [20, 21]. Another zinc finger transcription factor Tshz1 is required for the normal generation of $\mathrm{CB}^{+}$interneurons as well as the radial migration of multiple subtypes after neuroblasts ultimately reach the $\mathrm{OB}[22]$. Finally, the $\mathrm{TH}^{+}$ subpopulation requires both Pax6 and Er81 (Etv1) for their normal generation [2, 23, 24, 25, 26]. While these transcriptional regulators are expressed in the migrating and differentiating neuroblasts, the homeobox gene Gsx 2 is highly expressed by progenitor cells in the LGE and septum, and has been shown to be critical for the normal generation of many $\mathrm{OB}$ interneuron subtypes $[20,27,28,29,30,31,32]$. Specifically, it was demonstrated that the generation of $\mathrm{OB}$ interneurons is severely compromised when Gsx2 is absent in the dorsal LGE (dLGE) [31]. Gsx2 is also highly enriched in the VZ progenitor cells of the septum, which represents another important source of $\mathrm{OB}$ interneurons at perinatal time points $[2,7,9,10,14,33]$. Gsx2 is required for normal gene expression in the embryonic septum, including its downstream effector Ascl1 and related targets [34]. However, the function of Gsx2 in the specification of septum-derived $\mathrm{OB}$ interneurons has not been examined.

In this study, we utilized two genetic fate-mapping tools to investigate the LGE and septal contributions to OB interneuron diversity. In addition, by using a conditional knockout strategy, we examined the role of Gsx2 in the generation of septum-derived $\mathrm{OB}$ interneurons. Our data demonstrate that the LGE and septum give rise to $\mathrm{OB}$ interneuron subtypes differently, with the LGE being heterogeneous and the septum providing rather specifically the $\mathrm{CR}^{+}$interneurons of the GL. Additionally, we show that Gsx2 is required for the expansion of specified septal SVZ progenitors that give rise to $\mathrm{CR}^{+}$ interneurons.

\section{Methods \\ Animals}

Olig2 ${ }^{C r e /+}$ mice [35] and Gsx2e-CIE mice [36] were genotyped with the following primers: JaxCre-5' (5'-GCGGTC TGGCAGTAAAAACTATC-3') and JaxCre-3' (5'-CCAT GAGTGAACGAACCTGG-3'). Gs $x 2^{f l o x /+}, G s x 2^{R A /+}$ and $G s \times 2^{E G F P /+}$ alleles were genotyped as previously described $[31,32]$. Rosa ${ }^{\text {tdTomato }}$ (Ai14) mice were genotyped with the following primers: Rosa-tdTomato-5' (5'-GGCATTAAAGCAGCGTATCC-3') and Rosa-tdTomato-3' (5' -CTGTTC CTGTACGGCATGG-3') [37]. Zic3-lacZ BAC transgenic mice [38] were genotyped with the following primers: Bgal5' (5'-TGGGGAATGAATCAGGCCACGG-3') and Bgal3' (5'-GCGTGGGCGTATTCGCCAAGGA-3'). The Gsx1 knockout mice [39] and staged embryos were genotyped with the following primers: Gsx1-WT1 
(5'-CGGGTGAAGCACAAGAAAGAAG-3'), Gsx1-WT2 (5' -CCAATGGTCCTCTAAAAGGCG-3'), Gsx1-MT1 (5'-GGTTCATCATCACTAATCACGACG-3') and Gsx1MT2 (5'-CGCTGTTCTCCCTCTTCCTCATCTC-3').

For embryonic analysis, the morning of the vaginal plug observed was designated embryonic day (E)0.5. Embryos were fixed in $4 \%$ PFA overnight at $4{ }^{\circ} \mathrm{C}$, extensively rinsed in PBS and cryoprotected in $30 \%$ sucrose in PBS. Embryos were embedded in Neg-50 embedding medium for frozen tissue sectioning (Thermo Scientific) and coronal or horizontal sections were obtained at $12 \mu \mathrm{m}$ on a cryostat. Sections were mounted onto SuperFrost Plus Microscope Slides (Fisher Scientific) and stored at $-20{ }^{\circ} \mathrm{C}$ until processed. Postnatal brains were collected at P14. Brains were removed from skull and fixed in $4 \%$ PFA overnight at $4{ }^{\circ} \mathrm{C}$ before being extensively rinsed in PBS and cryoprotected in 20\% sucrose in PBS. Brains were then embedded in Neg-50 (Thermo Scientific) and coronal sections were obtained at $14 \mu \mathrm{m}$ on a cryostat. Again sections were mounted onto SuperFrost Plus Microscope Slides (Fisher Scientific) and stored at $-20{ }^{\circ} \mathrm{C}$ until staining.

\section{Immunohistochemistry}

Primary antibodies were used at the following concentrations: rabbit anti- $\beta$ gal, 1:1000 (Biogenesis); goat anti$\beta$ gal, 1:1000 (Biogenesis); chicken anti- $\beta$ gal, 1:500 (Abcam); rabbit anti-calbindin, 1:2500 (a gift from Dr. Piers Emson, Babraham Institute); goat anti-calretinin, 1:2000 (Millipore); rabbit anti-Gsx2, 1:5000 [40]; rabbit anti-Ki67, 1:1000 (Abcam); rabbit anti-Mef2c, 1:2000 (Protein Tech Group); mouse anti-Neurofilament (NFM), 1:200 (deposited to the Developmental Studies Hybridoma Bank by T.M. Jessell and J. Dodd); rabbit anti-Pax6, 1:1000 (Biolegend); goat anti-Sp8, 1:8000 (Santa Cruz Biotechnology); chicken anti-TH, 1:500 (Aves Labs), rabbit anti-panZic, 1:2000 (a gift from Dr. Stephen Brown, University of Vermont). Bright-field staining was obtained by using diaminobenzidine (DAB) as the chromogen following 2-h incubation in biotinylated goat anti-guinea pig (1:200, Vector Laboratories), horse anti-goat (1:200, Jackson Immunoresearch) or swine anti-rabbit (1:200, DAKO) and 1-h incubation in $\mathrm{ABC}$ solution (Vector Laboratories). Secondary antibodies for fluorescent staining (Jackson Immunoresearch) were donkey anti-rabbit antibodies conjugated with Alexa488, Cy3 or Alexa647, donkey anti-goat antibodies conjugated with Alexa488, Cy3 or Alexa647, donkey anti-chicken antibodies conjugated with Alexa488, Cy3 or Alexa647 and donkey anti-mouse antibody conjugated with $\mathrm{Cy} 3$. Fluorescent slides were covered with Fluoromount-G (SouthernBiotech). DAB slides were covered with DPX (Sigma). Confocal images were taken on NikonA1RGaAsP inverted microscope. Bright field images were captured using an Olympus BX50 microscope.

\section{Generation of Gsx1 antibody}

The Gsx1 antibody was raised in guinea pigs against the Cterminal peptide of human Gsx1, SAPQGCKCASLSSAKCSEDDDELPMSPSSSGKDDRDLTVTP (service provided by Pierce Custom Services, a subdivision of Life Technologies/ Thermo-Fisher Pierce) and used at 1:4000 dilution. Heated citrate retrieval solution was used to enhance the staining of Gsx1. This antibody was generated in Dr. Ronald Waclaw's lab at Cincinnati Children's Hospital Medical Center and its specificity was confirmed on Gsx1 mutants [39] at E18.5 (shown in Additional file 1: Figure S1). Control staining for Gsx1 protein in the ventral most LGE progenitors and in the developing hypothalamus (Additional file 1: Figure S1) is similar to previously characterized Gsx 1 gene expression $[28,30,32,41]$.

\section{Bromodeoxyuridine (BrdU) labeling}

Pregnant females were given one dose of BrdU (SigmaAldrich) $(100 \mathrm{mg} / \mathrm{kg})$ by intraperitoneal injection with embryos at E15.5 stage. Embryos were collected $1 \mathrm{~h}$ or $24 \mathrm{~h}$ later to examine proliferation and cell cycle retention [42]. Embryos were processed as described above. Cryosectioned $12 \mu \mathrm{m}$ tissues were treated $50 \mathrm{~min}$ for antigen-retrieval with $2 \mathrm{~N} \mathrm{HCl}$ at room temperature followed by PBS washes and incubation in rat anti-BrdU (1:200, BioRad) overnight.

\section{In situ hybridization}

In situ hybridization was performed as previously described [43]. Digoxigenin-labeled antisense probe against 3' 'UTR of Zic3 mRNA [38] was used on $12 \mu \mathrm{m}$ cryosections from E18.5 embryos.

\section{Quantification}

For the quantification of tdTomato fate mapped and Zic3-lacZ expressing $\mathrm{OB}$ interneuron subtypes in the GL, three animals were analyzed on the medial side of the OB. Three control and three Gs $x 2$ germline mutant (KO) embryos were analyzed for Gsx2 KO phenotype. Quantification of the embryonic (E18.5) OB phenotype in Gsx2 conditional mutants (cKOs) was performed on three controls and three Gsx 2 cKOs. Quantification of the P14 OB phenotype in Gsx2 cKOs was performed using Imaris (Bitplane) to analyze the GL on the medial side of OB of controls $(n=5)$ and Gsx2 cKOs $(n=5)$. Quantitative results were presented as mean \pm standard error of the mean (s.e.m.). Statistical significance was determined using the Student's $t$-test. 


\section{Results}

Zic3-lacZ marks a subpopulation of septal cells and their OB derivatives

Zic (1-4) genes are highly expressed in medial telencephalic progenitors, including those in the septum, but not in lateral progenitors, and have been implicated in OB interneuron development [44, 45]. Additionally, recent tamoxifen-regulated fate mapping studies using $\mathrm{Fgf8} \mathrm{CreER/+}^{-}$and $\mathrm{Fgf17} 7^{\mathrm{CreER} /+}$ alleles have revealed that, at early telencephalic stages, these medial telencephalic regions give rise to the septum, as well as a subpopulation of OB interneurons [46]. To label septal progenitors and their progeny, we utilized a lac $Z$ reporter under the control of cis-regulatory modules of the Zic3 gene. The Zic3-lacZ transgenic line was generated by inserting lacZ into the Zic3 locus in a bacterial artificial chromosome (BAC) [38]. We observed that $\beta$-galactosidase ( gal) from Zic3-lacZ transgene was largely restricted to the $\mathrm{Zic}^{+}$medial telencephalon, with only a few scattered cells occasionally observed in the ventricular zone (VZ) of the rostroventral LGE (Fig. 1A-G). We also detected Bgal staining in the striatum from E18.5 onward; however, this staining marked axons likely from the diencephalon, as confirmed by Neurofilament- $M$ double staining (Fig. 1C, inset and data not shown). In the medial progenitors, a gradient of $\beta$ gal staining was noticeable in the septal VZ, which was more uniform in the dorsal septum (Fig. 1A-G). Overall, the lacZ expression pattern was consistent with that of the endogenous Zic3 gene and overall Zic proteins (Fig. 1E-G) [44]. At E15.5, Bgal was robustly expressed in the septum. Indeed, we found many Gsx $2^{+}$progenitor cells in the septal VZ coexpressing $\beta$ gal (Fig. 1A, B). Similarly, many Gsx $2^{+}$progenitor cells were $\mathrm{Bgal}^{+}$in the E18.5 septum (Fig. 1C, D). These data suggested that Zic3-lacZ could be an effective tool to mark Gsx $2^{+}$progenitor cells in the septum and possibly their progeny. The septum is an important source of many neuronal cell types, including $\mathrm{OB}$ interneurons [9, 10, 14, 16, 33, 44, 46]. Moreover, Zic3 expressing cells originating from the septum have been shown to migrate toward the OB [44]. To understand whether medial progenitors in the septum contribute to the developing $\mathrm{OB}$, we immunostained horizontal sections from E18.5 Zic3lac $Z$ septum and $\mathrm{OB}$ with antibodies against $\beta$ gal and Sp8 and found many $\beta_{g a l^{+}}$cells expressing Sp8 migrating anteriorly from the septum to the $\mathrm{OB}$ in a pattern similar to Zic3 gene expression (inset in Fig. 1H). We also found many $\mathrm{Bgal}^{+}$cells in the germinal zone of the E18.5 OB, with a strong bias towards its medial side; moreover, in the GL we found $\beta_{g a l}{ }^{+}$cells distributed around the $\mathrm{OB}$ with a concentration on the medial side (Fig. 1J-O). Many $\mathrm{Bgal}^{+}$cells in the E18.5 OB were also labeled by panZic and expressed the transcription factor Sp8, suggesting they were indeed $\mathrm{OB}$ interneurons (Fig. 1J-O). Interestingly, few, if any, $\mathrm{Bgal}^{+}$cells were observed to express the GCL OB interneuron marker Mef2c [47, 48] (Fig. 1P). Thus, Zic3-lacZ mice provide a useful tool to study the $\mathrm{OB}$ interneuron progeny of septal progenitors.

\section{Differential contributions to $\mathrm{OB}$ interneuron subtypes from septal and LGE progenitors}

$\mathrm{OB}$ interneurons are physiologically and biochemically diverse and can be categorized into different subtypes based on various criteria including the biochemical markers they express, OB layer they occupy as well as neuronal connections they make $[3,4,5,6,7,19]$. Previous studies have suggested that the biochemical and morphological diversity of $\mathrm{OB}$ interneurons is determined by the location of the neural stem cell domains from which they originate $[9,10,16,49]$. To further explore the $\mathrm{OB}$ interneuron subtypes derived from embryonic and neonatal neural progenitor cells of distinct domains, we utilized Zic3-lacZ transgene as a genetic short-term fate map tool to study $O B$ interneuron subtypes from the septum. In addition, we recently generated the Gsx2e-CIE transgenic line, which robustly fate-maps LGE (but not septal) derivatives [36] and therefore allows us to assess LGE-derived OB interneuron subtypes in the same tissue as the Zic3-lacZ labeled interneurons. Indeed, we crossed the Gsx2e-CIE mice with a Rosa ${ }^{\text {tdTomato }}($ Ai14) reporter line [37] in the presence of Zic3-lacZ and found that LGE-lineage cells fate-mapped by tdTomato (hereafter referred to as tdTomato $^{+}$cells) and Bgal from Zic3-lacZ were largely nonoverlapping within the $\mathrm{OB}$ at $\mathrm{P} 14$, when the peak of neonatal $\mathrm{OB}$ interneuron neurogenesis occurs $[7,15]$ (Fig. 2A-E). Interestingly, although the $\mathrm{Bgal}^{+}$and tdTomato $^{+}$cells were mixed within the GL of the OB, $\mathrm{Bgal}^{+}$ and tdTomato $^{+}$neuroblasts in the RMS remained on the side from which they originated (i.e. medial and lateral, respectively) (Fig. 2A, inset). In the P14 OB, we found $\mathrm{Bgal}^{+}$cells were largely confined to the GL, with only scattered $\mathrm{Bgal}^{+}$cells in other OB layers, including the external plexiform layer (EPL) and the GCL (Fig. 2B). In fact, about $29.3 \pm 1.3 \%$ of the GL cells were $\mathrm{Bgal}^{+}$, whereas only $4.7 \pm 1.0 \%$ of the cells in GCL expressed $\beta$ gal. This is in line with the observation that few, if any, of the Mef2 $\mathrm{C}^{+}$granule cells were $\mathrm{Bgal}^{+}$in the E18.5 OB (Fig. 1P). In contrast, numerous LGE-derived tdTomato ${ }^{+}$ cells were found in both the GL and GCL (Fig. 2C-E) [36]. The GL enrichment of $\beta_{\text {gal }}^{+}$cells suggested that the GL was a major destination of septum-derived $\mathrm{OB}$ cells and therefore represented the focus of the present study. To examine the neuronal subtype identity of the $\mathrm{Bgal}^{+}$cells in the GL, we immunostained the P14 OB with antibodies against markers of periglomerular interneuron subtypes, $\mathrm{CB}, \mathrm{CR}$ and $\mathrm{TH}$ and found virtually no 

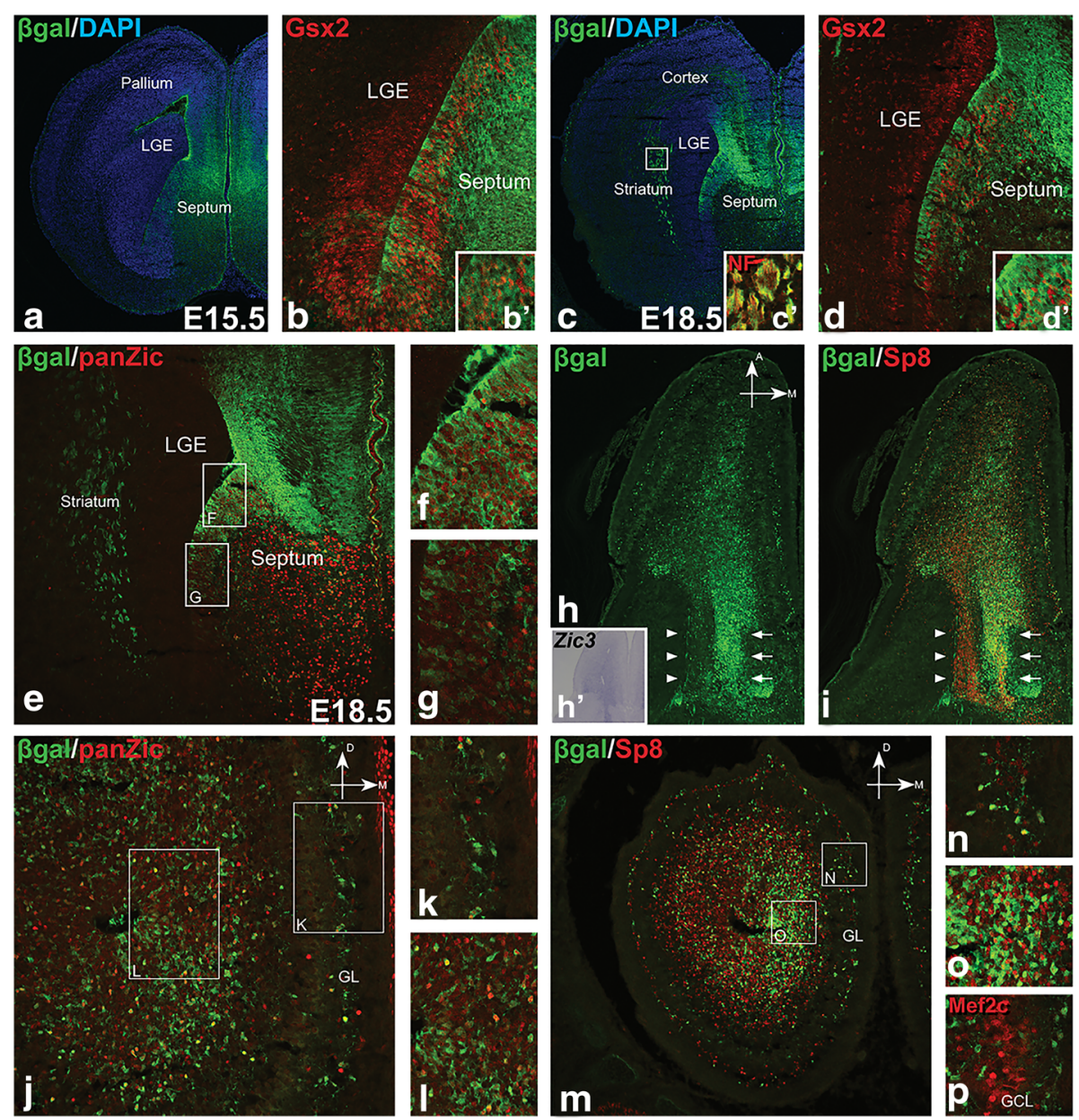

Fig. 1 Bgal from Zic3-lacZ marks the septal primordia and OB cells originating from septum. (a-d) Bgal was enriched in the E15.5 and E18.5 septum and co-localized with Gsx2 within VZ progenitors (b, d). Insets in (b) and (d) show high magnification views of septum (b') and (d'). Inset in (c) shows $\beta$ gal staining in the E18.5 striatum was found in axons ascending from diencephalon as evidenced by co-labeling with neurofilament (c'). (e-g) Bgal from Zic3lacZ displayed a dorsal to ventral gradient, similar to Zic proteins stained by panZic antibody, in the E18.5 septum. Boxes in (e) represent high magnification views in $(\mathbf{f})$ and $(\mathbf{g})$. (h, i) Horizontal section of E18.5 brain showed $\left.\beta g a\right|^{+}$cells migrating to the OB along the RMS and expressing Sp8 on the medial side (indicated by arrows) in a pattern similar to endogenous Zic3 gene expression shown in the inset ( $h^{\prime}$ ), whereas very few $\beta$ gall ${ }^{+}$cells were on the lateral side despite the presence of migrating Sp8 ${ }^{+}$cells (indicated by arrowheads). (J-L) Many $\beta g a l^{+}$and Zic ${ }^{+}$cells were found in the E18.5 OB in regions including the forming GL (k) and the germinal zone (I). Boxes in (j) represent high magnification views in (k) and (I). Most $\beta$ gall ${ }^{+}$cells were Zic ${ }^{+}$, while many Zic ${ }^{+}$cells were $\mathrm{Bgal}^{-}$. (m-o) Many $\beta \mathrm{Bgal}^{+}$cells in the forming GL (n) and germinal zone (o) of the OB co-expressed Sp8, constituting a subpopulation of Sp8 ${ }^{+}$ interneurons. Boxes in $(\mathbf{m})$ represent high magnification views in $(\mathbf{n})$ and $(\mathbf{o})$. (p) Mef2c ${ }^{+}$granule cells in the E18.5 OB did not express $\beta$ gal

$\mathrm{CB}^{+}$neurons were labeled by $\beta$ gal (Fig. 2F, L). In contrast, about $50.1 \pm 3.0 \%$ of the $\mathrm{CB}^{+}$cells were tdTomato $^{+}$(Fig. 2G, L), suggesting that a significant portion of $\mathrm{CB}^{+}$interneurons were derived from the LGE but not the septum. Similarly, we found few, if any, $\mathrm{TH}^{+}$(i.e. dopaminergic) neurons were $\mathrm{Bgal}^{+}$, whereas $40 \pm 0.6 \%$ of them were fate-mapped by tdTomato (Fig. $2 \mathrm{H}, \mathrm{I}, \mathrm{L}$ ), indicating that $\mathrm{TH}^{+} \mathrm{OB}$ interneurons are not septumderived and that the LGE serves as an important source for this neuronal subtype. The zinc finger transcription factor, $\mathrm{Sp} 8$, is expressed by many interneurons residing in both the GL and GCL [20]. We found that $85.7 \pm 2.6 \%$ of the $\mathrm{Bgal}^{+}$cells in the GL were $\mathrm{Sp} 8^{+}$(Fig. 2J). A small portion of
$\mathrm{Bgal}^{+}$cells were $\mathrm{Sp} 8^{-}$and displayed glial morphology together with immunoreactivity for the astrocyte marker GFAP (data not shown). The $\mathrm{Bgal}^{+} \mathrm{Sp} 8^{+}$double positive cells comprised about one third $(36.0 \%)$ of the total $\mathrm{Sp}^{+}$ cells in the GL, whereas about $25.9 \pm 2.0 \%$ of the $\mathrm{Sp}^{+} \mathrm{GL}$ neurons were tdTomato ${ }^{+}$(i.e. LGE-derivatives) (Fig. 2J, L). Many of the $\mathrm{Sp}^{+}$cells in the GL express the calcium binding protein $\mathrm{CR}[19,20]$, and $\mathrm{CR}^{+}$interneurons have been suggested to arise predominantly from the septum at postnatal time points $[9,10]$. Indeed, we found $22.2 \pm 1.8 \%$ of the $\mathrm{CR}^{+}$cells in the GL were $\mathrm{Bgal}^{+}$, accounting for about $30.5 \pm 4.0 \%$ of the $\mathrm{Bgal}^{+}$ cells, supporting a septal origin for at least a portion 

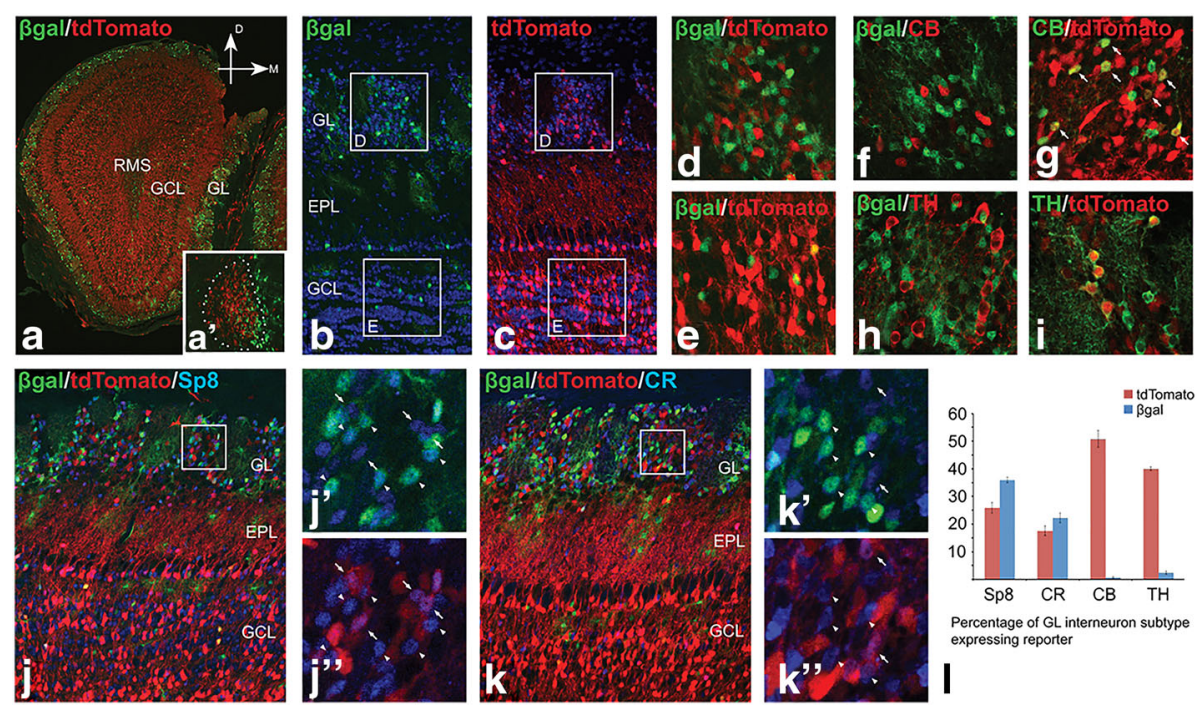

Fig. 2 Septum and LGE contribute to OB interneuron subtypes differently. (a) $\beta$ gal ${ }^{+}$(septum-derived) and tdTomato ${ }^{+}$(LGE-derived) cells distributed around the P14 OB, despite their bias towards medial and lateral migration, respectively (inset of RMS $\left(a^{\prime}\right)$ ). (b-e) $\beta$ gal and tdTomato expressing cells were largely separated and showed distinct layer localization in the P14 OB. Boxes in (b) and (c) represent high magnification views in (d) and (e). $\mathrm{Bgal}^{+}$cells were enriched in the $\mathrm{GL}(\mathbf{b}, \mathbf{d})$ whereas tdTomato ${ }^{+}$cells were abundant in both GL and GCL (c-e). (f, $\left.\mathbf{g}\right)$ LGE (tdTomato ${ }^{+}$) but not septum $\left(\beta \mathrm{gal}{ }^{+}\right)$progenitors gave rise to $\mathrm{CB}^{+}$PGCs. (h, i) TH ${ }^{+}$PGCs did not originate from septum. Instead, many of them were generated from the LGE. (j, $\left.\mathbf{k}\right)$ Both LGE (tdTomato ${ }^{+}$cells indicated by arrows) and septum (Bgal ${ }^{+}$cells indicated by arrowheads) contributed to Sp8 ${ }^{+}$and $\mathrm{CR}^{+}$PGCs. Boxes in (j) and (k) represent high magnification views in $\left(j^{\prime}, J^{\prime \prime}, K^{\prime}, K^{\prime}\right)$ respectively. (I) Quantification of each PGC subtypes from LGE- versus septum-lineages. Data represent the mean \pm s.e.m.

of this $\mathrm{OB}$ interneuron subtype (Fig. 2K, L). However, we also observed that about $17.6 \pm 1.7 \% \mathrm{CR}^{+}$interneurons were tdTomato $^{+}$, indicating that at least a subpopulation of these interneurons originate from the LGE (Fig. 2K, L). Taken together, these data support the notion that the LGE, more specifically the dLGE, gives rise to all three subtypes (i.e. TH, CB and CR) of GL interneurons, while the septum largely contributes to the CR subtype. Moreover, the dLGE provides neurons to populate both the GL and GCL, while the septum-derived progeny are specifically targeted to the GL.

\section{Impaired septum-derived $\mathrm{OB}$ neurogenesis in germline Gsx2 knockouts}

The homeobox gene Gsx2 is expressed at various levels by many VZ progenitor cells in the embryonic ventral telencephalon, including the LGE, MGE and septum [29, 40, 50], as well as in the postnatal dorsolateral SVZ (dISVZ), a derivative of the embryonic dLGE [48]. Previous studies revealed that Gsx2 is critical for the normal generation of many LGEderived cell types including OB interneurons, amygdalar intercalated cells and striatal projection neurons $[20,27,28,29,30,31,32,40,51]$. Despite that altered transcriptional profiles have been reported in the Gsx2-deficient septum [34], the role of Gsx2 in specifying septum-derived $\mathrm{OB}$ interneurons has not been well characterized. To test the requirement of Gs $x 2$ in the generation of OB cells from septum, we crossed the Zic3-lacZ allele onto Gsx2 germline knockout (Gsx2 KO, Gs $x 2^{R A / E G F P}$ or $G s x 2^{R A / R A}$ ) and control $\left(G s x 2^{R A /+}\right.$ or $\left.G s x 2^{E G F P /+}\right)$ mice $[31,32]$. We found reduced numbers of $\mathrm{Bgal}^{+}$cells in both the germinal zone and GL of the Gsx2 KO bulb at E18.5 (Fig. 3a, b). In agreement with previous studies [31,32], we also observed a $70 \%$ reduction (control: $96.9 \pm 11.4$ versus Gs $22 \mathrm{KO}$ : $26.8 \pm 7.0$ cells, $p=0.006$ ) of $\mathrm{Sp}^{+}$interneurons in the forming GL of the Gsx $2 \mathrm{KO} \mathrm{OB}$, which was concomitant with about a $60 \%$ loss (control: $21.3 \pm 3.4$ versus Gs $x 2 \mathrm{KO}$ : $7.8 \pm 3.3$ cells, $p=0.045$ ) of the $\mathrm{Bgal}^{+}$(i.e. septum-derived) population (Fig. 3c, d). These data supported the notion that Gsx2 is critical for the normal generation of septumderived $\mathrm{OB}$ interneurons as is the case for the LGEderived populations [31, 32].

\section{Reduced septum-derived interneurons in the $\mathrm{Olig}_{2}{ }^{\mathrm{Cre} /+}$ driven Gsx2 cKO OB}

As shown above, reduction in the numbers of $\mathrm{ggal}^{+}$and $\mathrm{Sp}^{+}$cells was observed in the E18.5 Gsx2 mutant OB. However, germline Gs $x 2$ mutant mice die at birth [52], preventing further analysis of the impact on the generation of mature $\mathrm{OB}$ phenotypes. Olig2 is robustly expressed not only by cells of the oligodendrocyte lineage [53], but also by many neurogenic progenitor cells in the VZ of ventral telencephalic regions including 


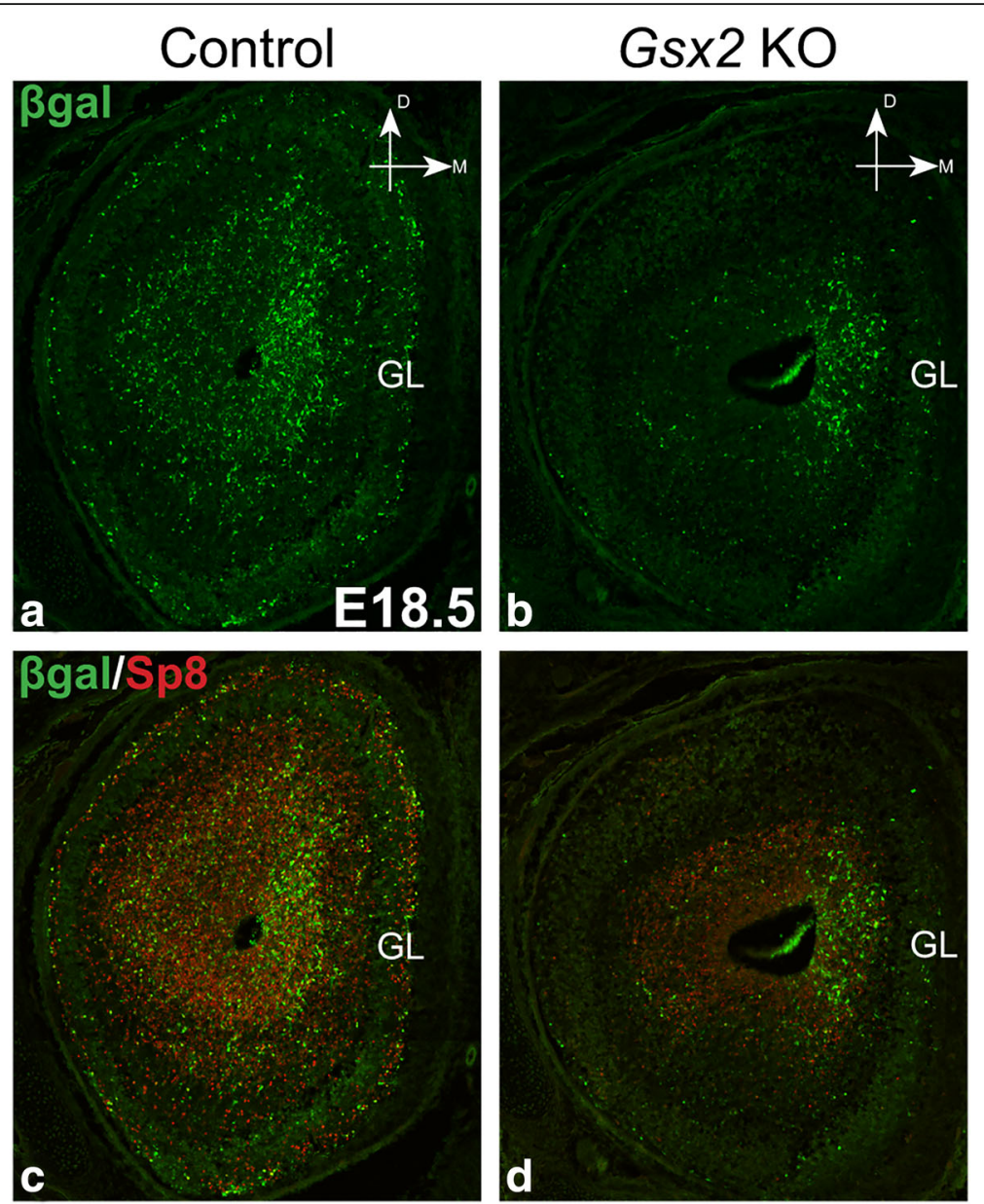

Fig. 3 Gsx2 germline knockout (KO) impairs the generation of septum-derived OB cells. a, b Gsx2 KO carrying the Zic3-lacZ allele showed a dramatic loss of $\left.\beta \mathrm{gal}\right|^{+}$cells in the E18.5 OB. c, d Septum-derived (i.e. $\beta g a l^{+}$) and non-septum-derived (i.e. $\beta g a l^{-}$) Sp8 ${ }^{+}$interneurons were also severely compromised in the E18.5 Gsx2 KO OB

the MGE, LGE and the septum [54, 55, 56]. Within the LGE, Olig2 is highly expressed in the VZ cells of the ventral (v)LGE while its expression in the dLGE is quite limited. Therefore we took advantage of an Olig2 $2^{\mathrm{Cre} /+}$ line [35] to selectively knockout Gsx2 in the septum and vLGE, while leaving it largely intact within the dLGE, as previously published [57]. We found a complete loss of Gsx2 in the E15.5 $\mathrm{Olig}_{2}^{\mathrm{Cre} /+} ; \mathrm{Gs} 2^{f_{\mathrm{x}} / \mathrm{fx}}$ (Gsx2 cKO) septum and vLGE (Fig. 4B) in comparison to $\mathrm{Olig}_{2}^{\mathrm{Cre} /+} ; \mathrm{Gs} \times 2^{\mathrm{fx} /+}$ (control) which show robust Gsx2 expression in septum and throughout the LGE (Fig. 4A). The expression of Gsx2 in the dLGE of the Gsx2 cKOs was largely intact (Fig. 4B). We observed a robust upregulation of the closely related family member, Gsx1, in the Gsx 2 cKO septum and vLGE (Fig. 4C, D). This is in line with previous studies that show Gsx1 can partially compensate for the loss of Gsx2 in the LGE [28, 30]. To investigate whether medial derived $\mathrm{OB}$ interneurons are compromised when Gs 2 is inactivated in the septum, we used Zic3-lacZ as a reporter and immunostained E18.5 control and Gsx2 cKO OB with antibodies against Sp8 and $\beta$ gal. In agreement with the observation in E18.5 Gsx2 KO OB, we found the number of $\mathrm{Bgal}^{+}$cells was reduced by $73 \%$ in the Gs $2 \mathrm{cKO}$ OB, as compared to controls (control: $26.1 \pm 2.6$ versus cKO: $7.1 \pm 2.0$ cells per field, $p=0.001$ ) (compare Fig. 5B with A). The total number of $\mathrm{Sp}^{+}$cells in the Gsx $2 \mathrm{cKO}$ GL was reduced by $31 \%$ (control: $70.4 \pm 3.8$ versus cKO: $48.3 \pm 3.3$ cells per field, $p=0.023$ ) (Fig. 5A-C). Importantly, the number of $\mathrm{Sp}^{+} \mathrm{Bgal}^{+}$double labeled cells (i.e. septum-derived) in the Gsx2 cKO GL was reduced by approximately $80 \%$ from control (control: $16.7 \pm 1.1$ versus cKO: $3.3 \pm 1.4$ cells per field, $p=0.003$ ) (Fig. $5 \mathrm{~A}-\mathrm{C}$ ). In contrast, the number of $\mathrm{Sp}^{+}{ }^{+} \mathrm{ggal}^{-}$GL cells in the Gs $x 2$ cKO OB, which are presumably derived largely from the dLGE, was not significantly different from that in the control (control: $53.7 \pm 4.3$ versus cKO: $45.0 \pm 3.5$ cells per field, $p=0.11$ ) (Fig. 5A-C).

At E18.5 the $\mathrm{OB}$ is undergoing development, and many interneurons that are specified during embryonic stages have not yet reached their final destination in the 


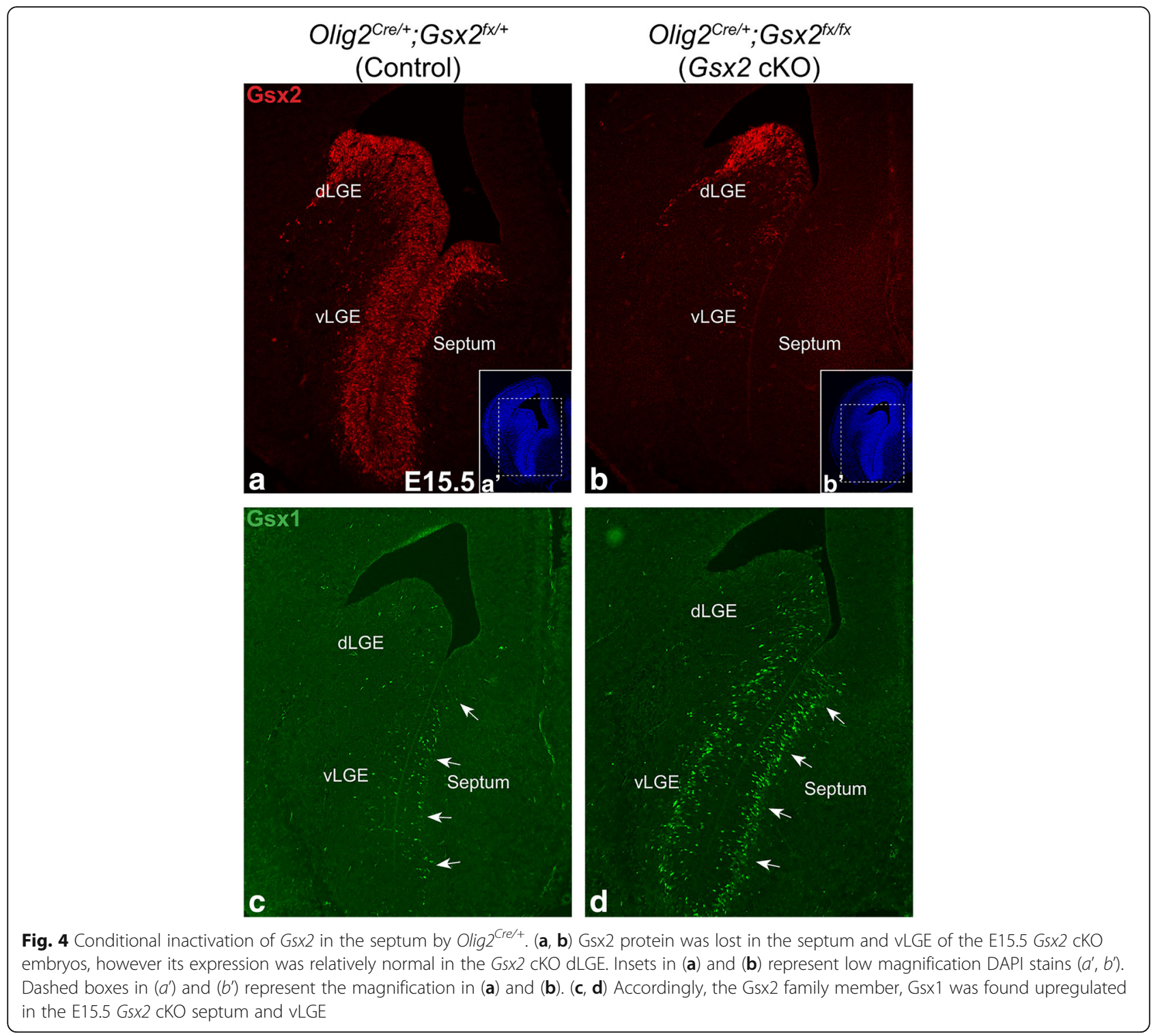

bulb and begun to express mature biochemical markers (e.g. $\mathrm{CB}, \mathrm{CR}$ and $\mathrm{TH}$ ). In addition, only a portion (about $20 \%$ ) of the OB interneurons in the rodent are born embryonically $[15,58]$, a significant amount of them are generated during the early postnatal stage $[7,15]$. Unlike Gsx2 germline knockouts, Olig2 ${ }^{\mathrm{Cre} /+} ; G s x 2^{f x / f x}$ (Gsx2 cKO) mice are viable after birth, allowing us to assess interneuron phenotypes in the postnatal OB. Therefore

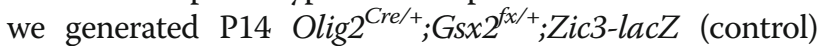
and Olig2 ${ }^{\mathrm{Cre} /+} ; \mathrm{Gsx}_{2}{ }^{f x / f x} ;$ Zic3-lacZ (Gsx2 cKO) mice and immunostained their $\mathrm{OB}$ with antibodies against different $\mathrm{OB}$ interneuron markers. We found a $15 \%$ reduction (control: $1987.8 \pm 54.4$ versus cKO: $1691.8 \pm 67.5$ cells $/ \mathrm{mm}^{2}$, $p=0.009)$ of $\mathrm{Sp}^{+}$interneurons along with a significant reduction (35\%) of $\mathrm{Bgal}^{+}$cells (control: $595.3 \pm 32.1$ versus cKO: $387.7 \pm 17.3$ cells $\left./ \mathrm{mm}^{2}, p=0.0005\right)$ in the GL of the
Gsx2 cKO OB (Fig. 5D-F). Furthermore, the compromised $\mathrm{Sp}^{+}$population was primarily due to the loss of septumderived $\mathrm{Sp} 8^{+}$periglomerular cells, as a $36 \%$ reduction (control: $506.1 \pm 30.5$ versus cKO: $324.5 \pm 18.4$ cells $/ \mathrm{mm}^{2}$, $p=0.001)$ of $\mathrm{Sp}^{+} \mathrm{Bgal}^{+}$double labeled cells in the GL was observed (Fig. 5D-F). In contrast, the $\mathrm{Sp}^{+} \beta \mathrm{gal}^{-} \mathrm{GL}$ cells (presumably dLGE-derived) in the mutants were not significantly different from control (control: $1481.7 \pm 40.0$ versus cKO: $1367.3 \pm 50.2$ cells $/ \mathrm{mm}^{2}, p=0.11$ ) (Fig. 5D-F). The postnatal septum is known to give rise to $\mathrm{CR}^{+}$interneurons in the GL (Fig. 2K, L) $[9,10,16]$. We also detected a $13 \%$ reduction (control: $849.9 \pm 26.7$ versus cKO: $741.5 \pm 34.2$ cells $/ \mathrm{mm}^{2}, p=0.037$ ) of $\mathrm{CR}^{+}$interneurons in the GL of the Gsx 2 cKO OB (Fig. 5G-I). Importantly, a $29 \%$ reduction of the septum-derived $\mathrm{CR}^{+} \beta \mathrm{gal}^{+}$cells was observed in the GL of the Gsx2 cKOs (control: 


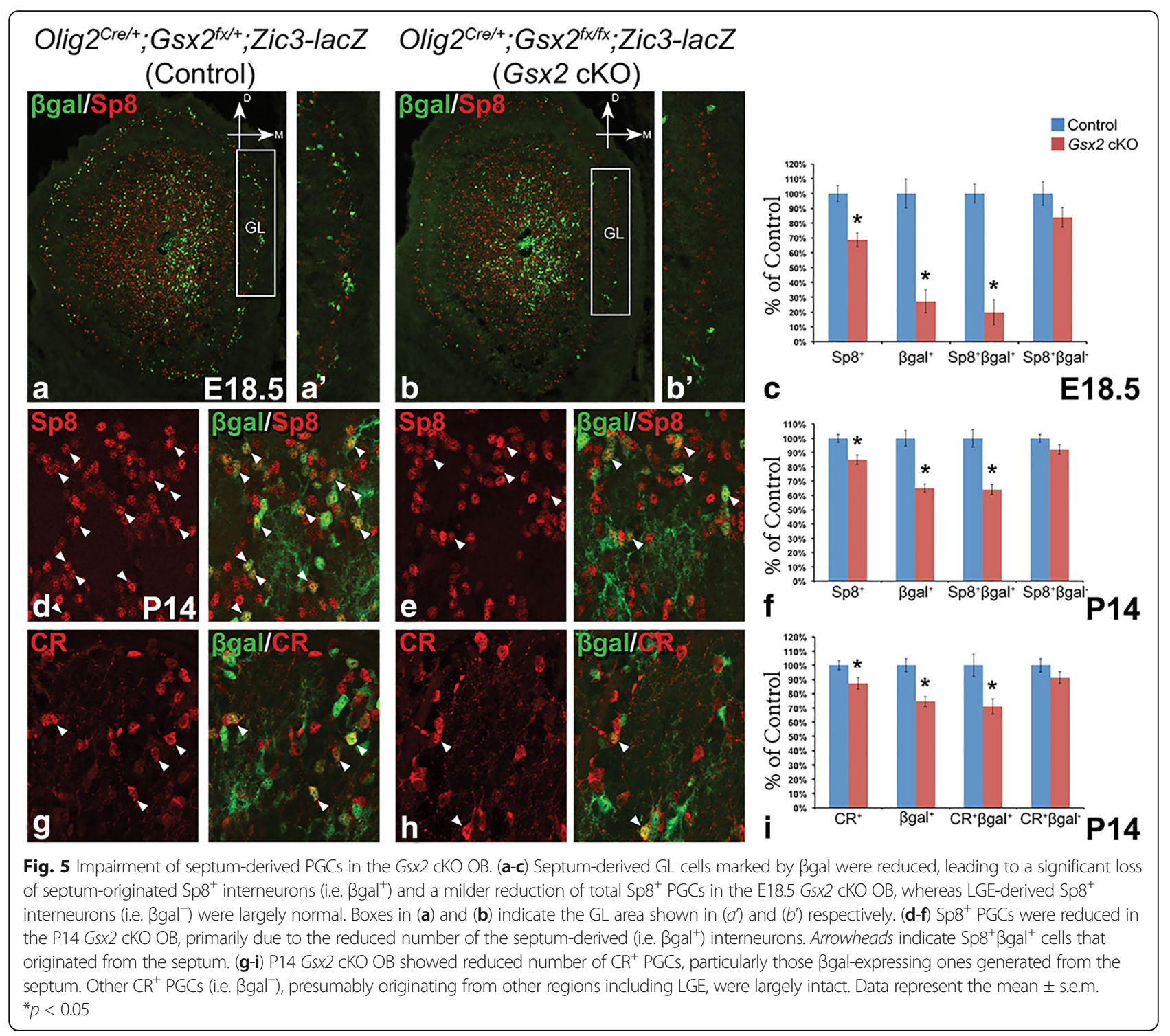

$171.2 \pm 13.5$ versus cKO: $121.7 \pm 9.2$ cells $/ \mathrm{mm}^{2}, p=0.016$ ), whereas the $\mathrm{CR}^{+} \mathrm{Bgal}^{-}$population (i.e. dLGE-derived) was not significantly different from that in control (control: $678.7 \pm 31.9$ versus cKO: $619.8 \pm 27.7$ cells $/ \mathrm{mm}^{2}, p=0.2$ ) (Fig. 5G-I). Few, if any, of the $\mathrm{CB}^{+}$or $\mathrm{TH}^{+}$interneurons in the GL originate from the septum (see Fig. 2F, H, L). Accordingly, normal numbers of $\mathrm{CB}^{+}$and $\mathrm{TH}^{+} \mathrm{GL}$ interneurons were observed in the Gs 2 cKO OB (data not shown).

\section{Conditional knockout of Gsx2 in the septum leads to development defects}

Gsx2 has been implicated in the generation of $\mathrm{OB}$ interneurons from the dLGE by regulating the temporal specification of $\mathrm{Sp} 8^{+}$neuroblasts [20, 31, 32, 50, 57]. To determine whether Gs $x 2$ inactivation by $\mathrm{Olig} 2^{\mathrm{Cre} /+} \mathrm{im}-$ pairs the normal specification and/or generation of $\mathrm{Sp} 8^{+}$ neuroblasts in the developing septum, we analyzed E15.5 control and Gsx 2 cKO embryos. Similar to what was found in the Gsx2-deficient LGE [28], we observed a dramatic loss of $\mathrm{Sp}^{+}$cells in the Gsx2 cKO septum, particularly at the rostral level where a large amount of $\mathrm{Sp}^{+}$cells were present in the control septum (arrowheads in Fig. 6). In contrast, Sp8 staining in the Gsx 2 cKO dLGE was comparable to that in the control embryos (arrows in Fig. 6), consistent with the fact that Gsx2 expression remains in the dLGE of conditional mutants. Gsx2 is critical for maintaining LGE progenitor cells in an undifferentiated state and promoting their self-renewal capacity [50]. In the absence of Gsx2, the embryonic LGE displays compromised cell proliferation and, thus, fails to establish a normal SVZ [28]. To investigate whether Gsx2 regulates proper cell proliferation in the developing septum, we pulsed pregnant females with one dose of BrdU at E15.5 and collected embryos $1 \mathrm{~h}$ 


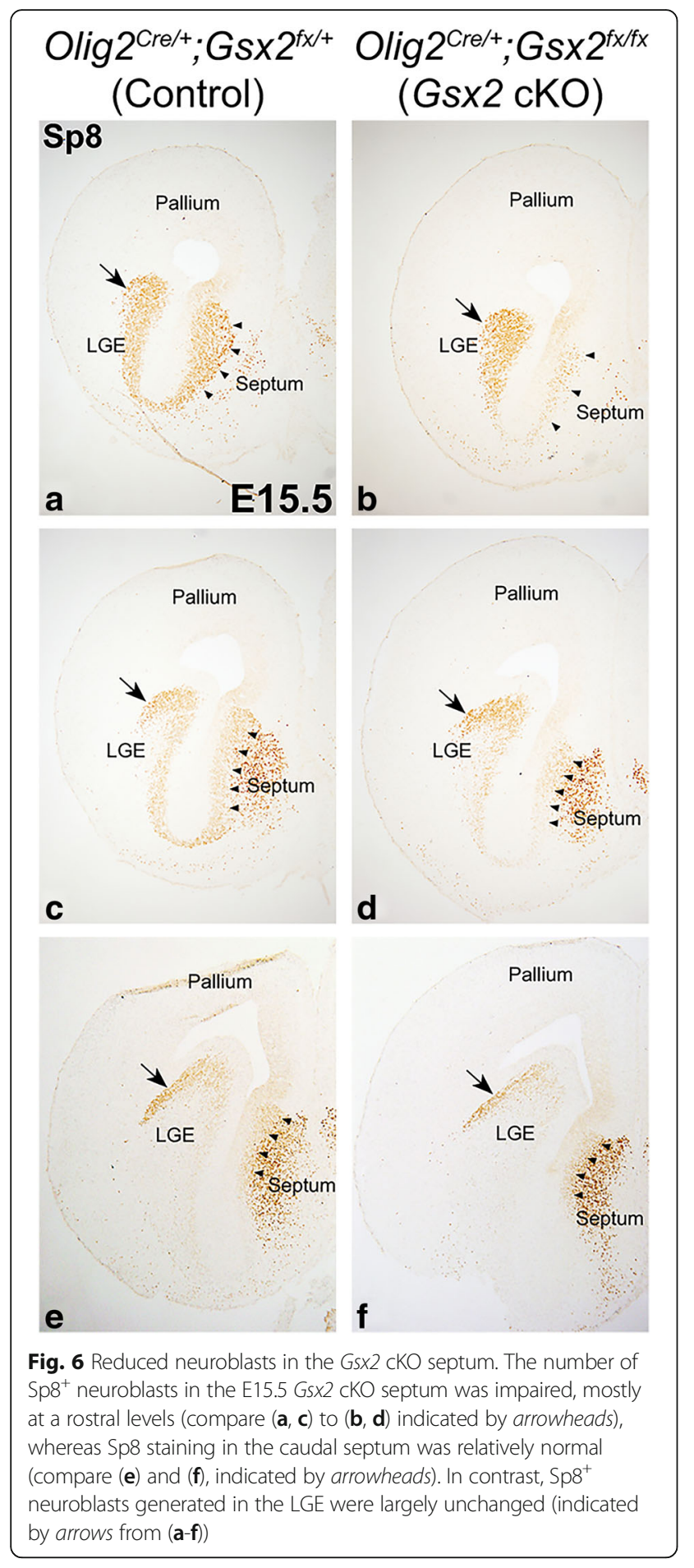

after BrdU administration to label cells in S-phase. Double staining for BrdU and the cell proliferation marker Ki67 demonstrated that cell proliferation in the septal VZ of Gsx2 cKO embryos was indistinguishable from that in the control (Fig. 7a-d). However, the numbers of $\mathrm{Ki}^{+} 7^{+}$and $\mathrm{BrdU}^{+}$cells in the SVZ were dramatically reduced in the Gsx2 cKO septum (Fig. 7a-d), suggesting the impairment of the formation of the secondary proliferative zone (i.e. SVZ) in the Gsx2-deficient septum. To determine whether cell cycle exit is altered in the Gsx2 cKO septum, one dose of BrdU was given at E15.5 and embryos were collected 24 h later [42]. Again, we performed double immunofluorescent staining for BrdU and Ki67 and calculated cell cycle retention index, measured by the percentage of $\mathrm{BrdU}^{+}$cells labeled at E15.5 remaining in cell cycle (i.e. $\mathrm{BrdU}^{+} \mathrm{Ki} 67^{+} / \mathrm{BrdU}^{+}$), in both control and Gsx2 cKO septum. While the cell cycle retention index in the $\mathrm{VZ}$ of control and Gs $x 2 \mathrm{cKO}$ septum were comparable (control: $29.4 \%$ versus cKO: $31.6 \%, p=0.26$ ) at E16.5, we found a reduced percentage of $\mathrm{BrdU}^{+}$cells remaining in the cell cycle (i.e. $\mathrm{Ki}^{+} 7^{+}$) within the SVZ of the Gsx2 cKO septum (control: $38.4 \%$ versus cKO: 25.1\%, $p=0.0006$ ) (Fig. 7e-g). These findings indicate that Gsx2 is required for the correct establishment of a proliferative SVZ in the septum. Moreover, proliferative progenitors in the Gsx2-deficient septal SVZ appear to exit the cell cycle prematurely, thus limiting the number of septum-derived $O B$ interneurons, which is in line with the observed $\mathrm{OB}$ phenotype in Gsx2 germline and cKO mutants.

\section{Discussion}

In this study, we investigated the regional contributions to $\mathrm{OB}$ interneuron diversity at embryonic and neonatal stages using both long-term and short-term genetic fatemapping approaches. Our results indicate that the septum contributes to subpopulations of $\mathrm{Sp}^{+}$and $\mathrm{CR}^{+}$ interneurons in the GL but not to their $\mathrm{CB}^{+}$or $\mathrm{TH}^{+}$ counterparts. In contrast, the dLGE contributes to all these subtypes, including $\mathrm{CB}^{+}, \mathrm{CR}^{+}$and $\mathrm{TH}^{+}$, as well as large numbers of interneurons that occupy both the GL and GCL. The homeobox gene Gsx2 has been suggested to be critical for the normal generation of OB interneurons from the embryonic dLGE [31, 32], however, its role in the generation of septum-derived $O B$ interneurons has not been described. By conditionally inactivating Gsx2 in the septum while largely preserving its expression in the dLGE, we found reduced numbers of septum-derived $\mathrm{Sp}^{+}$and $\mathrm{CR}^{+} \mathrm{OB}$ interneurons in the GL. In addition, our data suggest that the $\mathrm{OB}$ interneuron defects (reduction of $\mathrm{CR}^{+} \mathrm{GL}$ cells) observed in Gs $x 2 \mathrm{cKO}$ animals result from the impaired proliferation of OB interneuron progenitors in the septal SVZ.

$\mathrm{OB}$ interneurons are generated from both dLGE and septum embryonically [8, 14, 16, 20, 31, 33]. It has been suggested that $\mathrm{OB}$ interneurons of different subtypes originate from distinct progenitor/neural stem cell domains in the postnatal telencephalon $[9,10,16]$. Although many studies have attempted to address this notion, few genetic approaches have been taken to characterize the origins of $\mathrm{OB}$ interneuron subtypes 


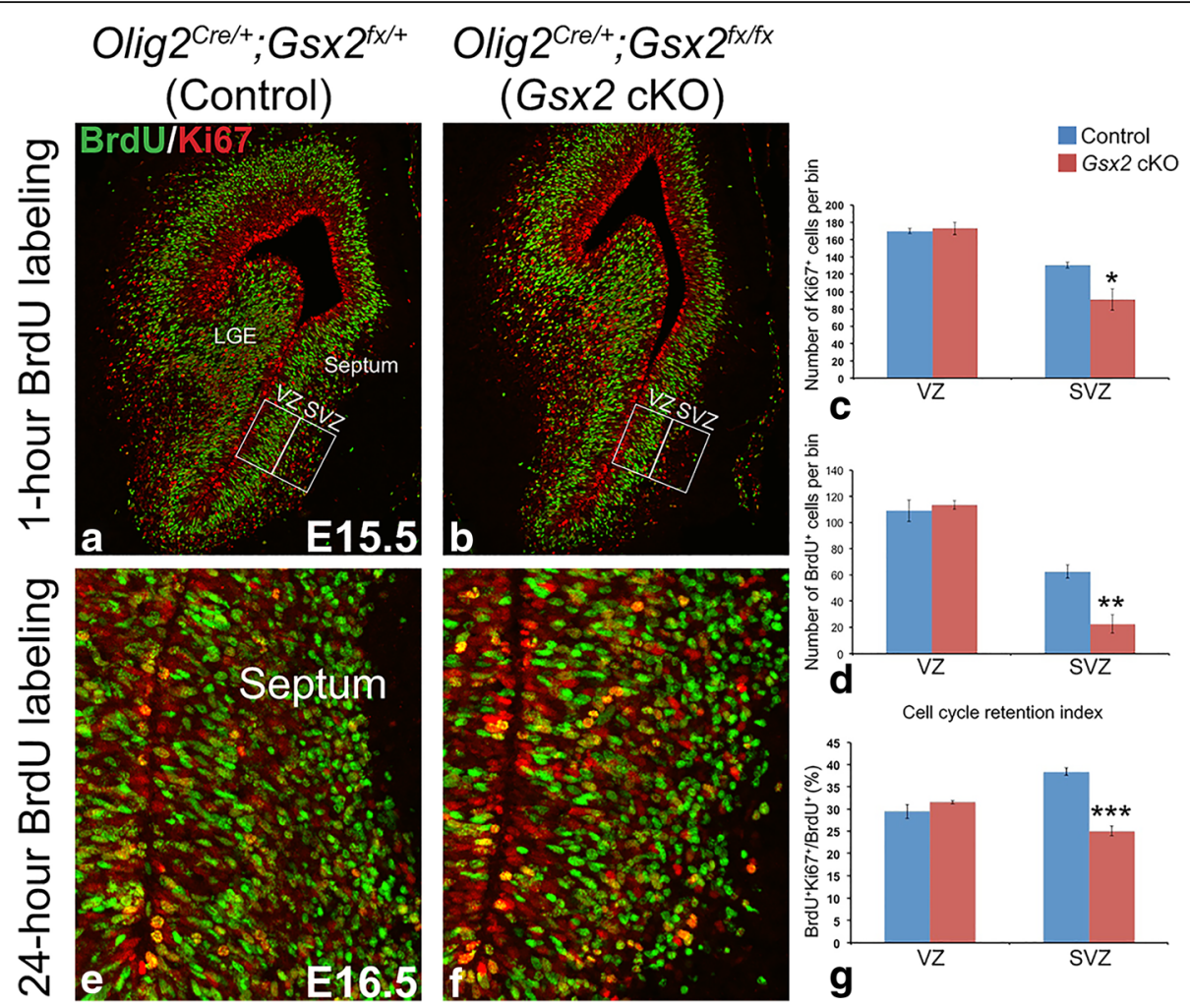

Fig. 7 Impaired cell proliferation in the Gsx2 CKO septum. a-d Gsx2 cKO septum showed reduced cell proliferation in the SVZ, but not in the VZ, at E15.5, as revealed by Ki67 and BrdU staining after one-hour BrdU labeling. The VZ was defined according to the apical ventricular surface and the basal region where S-phase BrdU ${ }^{+}$nuclei were enriched. The same size box was placed adjacent to the VZ to represent the SVZ. e-g Cell cycle retention index was relatively normal in the VZ but decreased in the SVZ of the Gsx2 cKO septum $24 \mathrm{~h}$ after E15.5 BrdU administration. Data represent the mean \pm s.e.m. ${ }^{*} p<0.05,{ }^{* *} p<0.01,{ }^{* * *} p<0.005$

generated during embryonic and the subsequent neonatal periods, when many $\mathrm{OB}$ interneurons are born [7, 15]. Recently, a pan-antibody against Zic proteins was used to identify $\mathrm{OB}$ interneurons derived from septum [10]. Although panZic ${ }^{+}$cells were restricted in the E18.5 septum and most of the $\mathrm{Bgal}^{+}$cells from the Zic3-lacZ lineage were also panZic ${ }^{+}$in the OB GL, we detected some panZic ${ }^{+}$cells in the P14 dlSVZ (data not shown). While panZic staining is enriched in the septum and remains a useful tool to examine septum derived cells in postnatal $\mathrm{OB}$, we took a more specific approach using Zic3 reporter mice expressing ßgal from a Zic3 BAC construct [38]. We found $\beta$ gal expression to be largely restricted to the medial side of the telencephalon, including the septum, with only occasional clones observed in the ventral-most portion of the embryonic LGE. In addition, no ectopic $\beta$ gal signal was found in the P14 dlSVZ (data not shown). It was noticeable that Bgal from the Zic3-lacZ transgene showed a dorsal-high to ventral-low gradient in the septum, and although this pattern was consistent with that of endogenous Zic proteins, its expression was mosaic. Despite this, a considerable portion of the $\mathrm{Sp} 8^{+}$cells in the septal SVZ were $\mathrm{Bgal}^{+}$(data not shown). In the OB, $\beta$ gal signal represents both persistent and down-regulated Zic gene expression. Most of the $\mathrm{Bgal}^{+}$cells were panZic ${ }^{+}$, but some of the cells in which $\beta$ gal was persistent were not and thus likely represent a short-term fate map of the Zic lineage. Thus, Zic3-lacZ appears to be a reliable short-term fate map tool for studying septal cells and their $\mathrm{OB}$ derivatives.

By combining the Zic3-lacZ allele together with the recently characterized LGE driver Gsx2e-CIE [36], we assessed the unique contributions to the $\mathrm{OB}$ interneuron populations from septum and LGE separately. Our results, at both E18.5 and P14, indicate that septum primarily contributes to $\mathrm{OB}$ interneurons (i.e. $\mathrm{Bgal}^{+}$) in the GL, whereas dLGE-derived interneurons (i.e. tdTomato $^{+}$) were observed to populate all OB layers, including the GL and GCL. Furthermore, our findings indicate that septum-derived $\mathrm{OB}$ progenitors are rather limited in potential to generate $\mathrm{Sp} 8^{+}$and $\mathrm{CR}^{+}$cells in the GL, whereas the $\mathrm{dLGE}$ progenitors give rise to all three major GL subtypes, namely $\mathrm{CB}^{+}, \mathrm{TH}^{+}$and interestingly also a subpopulation of $\mathrm{CR}^{+}$periglomerular cells. Merkle et al. $[9,10]$ have previously suggested that the septum 
represents an exclusive source for $\mathrm{CR}^{+} \mathrm{OB}$ interneurons. These studies examined the postnatal contributions of septal progenitors, while our study includes both embryonic and early postnatal time points. We found that the septum and dLGE lineages both contribute to $\mathrm{Sp} 8^{+} \mathrm{OB}$ interneurons, among which about half also express $\mathrm{CR}$ [20]. In addition, $\mathrm{CR}^{+}$cells have been detected in the E18.5 dLGE, and similar stage Ascl1 mutants which show aberrant Gsx2 and Sp8 expression in the dLGE, also exhibit enhanced $C R$ staining in the dLGE and $O B$ [32]. The notion that the dLGE represents a separate source of $\mathrm{CR}^{+} \mathrm{OB}$ interneurons is also supported by our findings that many $\mathrm{CR}^{+}\left(\beta_{\mathrm{gal}}{ }^{-}\right)$interneurons were present in the Gsx2 cKO mice, in which Gsx2 remained largely intact in the dLGE. In fact, Zic3-lacZ (i.e. septal) and Gsx2e-CIE (i.e. dLGE) lineages together account for only about $40 \%$ of the total $\mathrm{CR}^{+}$interneurons in the GL. While this could be due, in part, to incomplete recombination/transgene expression, it is also possible that other telencephalic regions may provide a separate subpopulation of $\mathrm{CR}^{+} \mathrm{OB}$ interneurons. For example, a previous study using a transplantation approach suggested that the pallium is able to contribute to $\mathrm{CR}^{+}$ $\mathrm{OB}$ interneurons [2].

The specification of diverse $\mathrm{OB}$ interneuron subtypes has been suggested to be the result of combinatory effects of many transcription factors referred as transcription factor codes [19, 59]. Our findings that both dLGE and septum give rise to $\mathrm{CR}^{+}$interneurons in the GL which are distinguished, in part, by the expression of Zic proteins in the septum-derived subpopulation raises the question whether $\mathrm{CR}^{+}$interneurons with distinct telencephalic origins are phenotypically/physiologically different.

In the embryonic ventral telencephalon, Gs $x 2$ is highly expressed by progenitor cells in the VZ of the septum and LGE with a high dorsal to low ventral gradient in each region. We noticed co-localization of $\beta$ gal from the Zic3-lacZ transgene and Gsx2 in the septal VZ as well as maintained Bgal expression in the embryonic and postnatal $\mathrm{OB}$ which allowed us to use this reporter mouse as a short-term genetic fate map tool to study the contribution of $\mathrm{Gsx}^{+}$progenitors in the septum to their $\mathrm{OB}$ progeny. We found that septum-derived (i.e. Bgalexpressing) $\mathrm{Sp}^{+}$and $\mathrm{CR}^{+} \mathrm{OB}$ interneurons were reduced in the GL when Gs $x 2$ was selectively inactivated in the septum using an $\mathrm{Olig} 2^{\mathrm{Cre} /+}$ driver. Similarly, we observed decreased panZic-labeled $\mathrm{Sp}^{+}$cells in the forming GL of the E18.5 Gsx2 cKO OB (data not shown). Moreover, this phenotype was not due to a lack of Zic proteins or $\beta$ gal expression, as both remained in the Gsx2 cKO septal progenitors (data not shown). Therefore, these findings indicate an important role for Gsx2 in regulating normal OB interneuron generation from the septum, specifically the septum-derived $\mathrm{CR}^{+}$ periglomerular cells. Interestingly, the reduction of septum-derived $\mathrm{Sp} 8{ }^{+}$interneurons in the P14 Gs $x 2 \mathrm{cKO}$ $\mathrm{OB}$ was not as pronounced as that in the E18.5 OB. This is probably due to the upregulation of Gsx1, a family member of Gsx2, which has been shown to partially compensate for the loss of Gs $x 2$ in the LGE via upregulation at the VZ/SVZ boundary [28, 30, 32, 50, 57]. Indeed, Gsx1 upregulation was already detected in E15.5 embryos also at the VZ/SVZ boundary of the Gsx 2 cKO septum. In addition, Gsx-independent neurogenesis may also occur in the septum during later developmental stages. In fact, Gsx1 does not compensate for the loss of Gsx2 in the adult dlSVZ [48], suggesting a Gsx-independent neurogenesis program for some $O B$ interneuron subtypes. We observed reduced $\mathrm{Sp} 8^{+}$cells and impaired cell cycle kinetics in the SVZ of the Gsx2-deficient septum of E15.5 embryos. Similar phenotypes were also reported in the Gsx2 knockout LGE [20, 28, 31, 32, 57]. Interestingly, we found a reduced cell cycle retention index in SVZ but not in VZ progenitors of the Gsx2 cKO septum. Given that Gsx2 is present in primary progenitor cells (i.e. VZ), our results suggest that Gsx2 regulates $\mathrm{OB}$ interneuron generation from the septum by enhancing indirect neurogenesis and/or indirectly influencing the proliferation capacity of basal (i.e. SVZ) progenitors derived from Gsx2 expressing VZ cells. One possible mechanism is that Gsx2 may repress or reduce Gsx1 expression. Despite that Gsx1 shares similar function with Gsx2 in telencephalic patterning, it promotes progenitor maturation and neurogenesis while Gsx2 helps to maintain progenitors in an undifferentiated state [50]. Therefore, the Gsx2-deficient primary progenitors with upregulated Gsx1 may bias towards direct neurogenic cell division and give rise to SVZ cells that exhibit reduced proliferative capacity.

\section{Conclusions}

This study provides evidence that the embryonic/neonatal septum and dLGE contribute to OB interneuron diversity differently. Specifically, the septum contributes $\mathrm{CR}^{+}$cells to the GL, while the dLGE gives rise to interneurons that occupy both the GCL and GL as well as the 3 main subtypes of $\mathrm{GL}$ interneurons $\left(\mathrm{CB}^{+}, \mathrm{CR}^{+}\right.$and $\left.\mathrm{TH}^{+}\right)$. Moreover, our findings indicate a role for Gsx2 in septal VZ progenitors for the generation of proliferative SVZ progenitors specified to generate $\mathrm{CR}^{+} \mathrm{GL}$ interneurons in the $\mathrm{OB}$.

\section{Additional file}

Additional file 1: Figure S1. Characterization of Gsx1 specific antibody. Immunostaining for GsX1 in the telencephalon and diencephalon reveals positive cells in the ventral most LGE and developing hypothalamus $\left(G s \times 1^{+/+}\right)$at E18.5 (A, C). No Gsx1 positive cells are detected in GsX1 mutant $\left(G s \times 1^{-/-}\right)$forebrain regions (B, D). (TIFF $\left.9369 \mathrm{~kb}\right)$ 


\section{Abbreviations}

BAC: Bacterial artificial chromosome; BrdU: Bromodeoxyuridine; CB: Calbindin; cKO: Conditional knockout; CR: Calretinin; dLGE: Dorsal lateral ganglionic eminence; E: Embryonic day; GCL: Granule cell layer; GL: Glomerular layer; LGE: Lateral ganglionic eminence; MGE: Medial ganglionic eminence; OB: Olfactory bulb; PGC: Periglomerular cell; RMS: Rostral migratory stream; SVZ: Subventricular zone; TH: Tyrosine hydroxylase; VZ: Ventricular zone: ßgal: $\beta$-galactosidase

\section{Acknowledgements}

We thank Drs. Tom Jessell and Ben Novitch for the Olig2 ${ }^{\text {Cre/t }}$ mice. We also thank Drs. Piers Emson and Stephen Brown for providing antibodies.

\section{Funding}

This work is supported by the National Institutes of Health $(\mathrm{NIH})$ grant R01NS044080 to K.C.

\section{Availability of data and materials}

Data sharing not applicable to this article as no datasets were generated or analyzed during the current study.

\section{Authors' contributions}

SQ and RRW performed the experiments. SMW provided essential reagents. $\mathrm{SQ}, \mathrm{RRW}$ and KC conceived of the study, and participated in its design and data interpretation. SQ drafted the manuscript and SMW, RRW and KC edited and revised the manuscript. All authors read and approved the final manuscript.

\section{Ethics approval}

All animal work was approved by the Cincinnati Children's Hospital Medical Center's IACUC committee (protocol\# IACUC2015-0098).

\section{Consent for publication}

Not applicable.

\section{Competing interests}

The authors declare that they have no competing interests.

\section{Publisher's Note}

Springer Nature remains neutral with regard to jurisdictional claims in published maps and institutional affiliations.

\begin{abstract}
Author details
${ }^{1}$ Divisions of Developmental Biology, Cincinnati Children's Hospital Medical Center, University of Cincinnati College of Medicine, Cincinnati, OH 45229, USA. ${ }^{2}$ Molecular and Developmental Biology Graduate Program, University of Cincinnati College of Medicine, Cincinnati, OH 45229, USA. ${ }^{3}$ Neurosurgery, Cincinnati Children's Hospital Medical Center, University of Cincinnati College of Medicine, Cincinnati, OH 45229, USA. ${ }^{4}$ Experimental Hematology and Cancer Biology, Cincinnati Children's Hospital Medical Center, University of Cincinnati College of Medicine, Cincinnati, OH 45229, USA. ${ }^{5}$ Department of Pediatrics and Medical and Molecular Genetics, Indiana University School of Medicine, Indianapolis, IN 46202, USA.
\end{abstract}

Received: 15 June 2017 Accepted: 1 August 2017

Published online: 16 August 2017

\section{References}

1. Lledo PM, Gheusi G, Vincent JD. Information processing in the mammalian olfactory system. Physiol Rev. 2005;85:281-317.

2. Kohwi M, Petryniak MA, Long JE, Ekker M, Obata K, Yanagawa Y, Rubenstein $J$, Alvarez-Buylla A. A subpopulation of olfactory bulb GABAergic interneurons is derived from Emx1- and Dlx5/6-expressing progenitors. J Neurosci. 2007;27:6878-91.

3. Parrish-Aungst S, Shipley MT, Erdelyi F, Szabo G, Puche AC. Quantitative analysis of neuronal diversity in the mouse olfactory bulb. J Comp Neurol. 2007:501:825-36.

4. Kosaka K, Toida K, Aika Y, Kosaka T. How simple is the organization of the olfactory glomerulus?: the heterogeneity of so-called periglomerular cells. Neurosci Res. 1998;30:101-10.
5. Schoppa NE, Urban NN. Dendritic processing within olfactory bulb circuits. Trends Neurosci. 2003;26:501-6.

6. Wachowiak M, Shipley MT. Coding and synaptic processing of sensory information in the glomerular layer of the olfactory bulb. Semin Cell Dev Biol. 2006;17:411-23.

7. Lledo PM, Merkle FT, Alvarez-Buylla A. Origin and function of olfactory bulb interneuron diversity. Trends Neurosci. 2008;31:392-400.

8. Stenman J, Toresson H, Campbell K. Identification of two distinct progenitor populations in the lateral ganglionic eminence: implications for striatal and olfactory bulb neurogenesis. J Neurosci. 2003;23:167-74.

9. Merkle FT, Mirzadeh Z, Alvarez-Buylla A. Mosaic organization of neural stem cells in the adult brain. Science. 2007;317:381-4.

10. Merkle FT, Fuentealba LC, Sanders TA, Magno L, Kessaris N, Alvarez-Buylla A. Adult neural stem cells in distinct microdomains generate previously unknown interneuron types. Nat Neurosci. 2014;17:207-14.

11. Blanchart A, De Carlos JA, López-Mascaraque L. Time frame of mitral cell development in the mice olfactory bulb. J Comp Neurol. 2006:496:529-43.

12. Imamura F, Ayoub AE, Rakic P, Greer CA. Timing of neurogenesis is a determinant of olfactory circuitry. Nat Neurosci. 2011;14:331-7.

13. Imamura F, Greer CA. Pax6 regulates Tbr1 and Tbr2 expressions in olfactory bulb mitral cells. Mol Cell Neurosci. 2013;54:58-70.

14. Long JE, Garel S, Alvarez-Dolado M, Yoshikawa K, Osumi N, Alvarez-Buylla RJL. Dlx-dependent and -independent regulation of olfactory bulb interneuron differentiation. J Neurosci. 2007;27:3230-43.

15. Batista-Brito R, Close J, Machold R, Fishell G. The distinct temporal origins of olfactory bulb interneuron subtypes. J Neurosci. 2008;28:3966-75.

16. Fuentealba LC, Rompani SB, Parraguez Jl, Obernier K, Romero R, Cepko CL, AlvarezBuylla A. Embryonic origin of postnatal neural stem cells. Cell. 2015;161:1644-55.

17. Doetsch F, Alvarez-Buylla A. Network of tangential pathways for neuronal migration in adult mammalian brain. Proc Natl Acad Sci U S A. 1996:93:14895-900.

18. Hu H, Tomasiewicz H, Magnuson T, Rutishauser $U$. The role of polysialic acid in migration of olfactory bulb interneuron precursors in the subventricular zone. Neuron. 1996;16:735-43.

19. Allen ZJ 2nd, Waclaw RR, Colbert MC, Campbell K. Molecular identity of olfactory bulb interneurons: transcriptional codes of periglomerular neuron subtypes. J Mol Histol. 2007;38:517-25.

20. Waclaw RR, Allen ZJ 2nd, Bell SM, Erdélyi F, Szabó G, Potter SS, Campbell K. The zinc finger transcription factor Sp8 regulates the generation and diversity of olfactory bulb interneurons. Neuron. 2006:49:503-16.

21. Li X, Sun C, Lin C, Ma T, Madhavan MC, Campbell K, Yang Z. The transcription factor Sp8 is required for the production of parvalbuminexpressing interneurons in the olfactory bulb. J Neurosci. 2011;31:8450-5.

22. Ragancokova D, Rocca E, Oonk AM, Schulz H, Rohde E, Bednarsch J, Feenstra I, Pennings RJ, Wende H, Garratt AN. TSHZ1-dependent gene regulation is essential for olfactory bulb development and olfaction. J Clin Invest. 2014;124:1214-27.

23. Dellovade TL, Pfaff DW, Schwanzel-Fukuda M. Olfactory bulb development is altered in small-eye (Sey) mice. J Comp Neurol. 1998; 402:402-18.

24. Hack MA, Saghatelyan A, de Chevigny A, Pfeifer A, Ashery-Padan R, Lledo PM, Götz M. Neuronal fate determinants of adult olfactory bulb neurogenesis. Nat Neurosci. 2005;8:865-72.

25. Brill MS, Snapyan M, Wohlfrom H, Ninkovic J, Jawerka M, Mastick GS, AsheryPadan R, Saghatelyan A, Berninger B, Götz M. A dlx2- and pax6-dependent transcriptional code for periglomerular neuron specification in the adult olfactory bulb. J Neurosci. 2008;28:6439-52.

26. Cave JW, Akiba Y, Banerjee K, Bhosle S, Berlin R, Baker H. Differential regulation of dopaminergic gene expression by Er81. J Neurosci. 2010;30:4717-24.

27. Corbin JG, Gaiano N, Machold RP, Langston A, Fishell G. The Gsh2 homeodomain gene controls multiple aspects of telencephalic development. Development. 2000;127:5007-20.

28. Toresson H, Campbell K. A role for Gsh1 in the developing striatum and olfactory bulb of Gsh2 mutant mice. Development. 2001;128: 4769-80.

29. Yun K, Potter S, Rubenstein JL. Gsh2 and Pax6 play complementary roles in dorsoventral patterning of the mammalian telencephalon. Development. 2001;128:193-205

30. Yun K, Garel S, Fischman S, Rubenstein JL. Patterning of the lateral ganglionic eminence by the Gsh1 and Gsh2 homeobox genes regulates striatal and olfactory bulb histogenesis and the growth of axons through the basal ganglia. J Comp Neurol. 2003;461:151-65. 
31. Waclaw RR, Wang B, Pei Z, Ehrman LA, Campbell K. Distinct temporal requirements for the homeobox gene Gsx2 in specifying striatal and olfactory bulb neuronal fates. Neuron. 2009;63:451-65.

32. Wang B, Waclaw RR, Allen ZJ 2nd, Guillemot F, Campbell K. Ascl1 is a required downstream effector of Gsx gene function in the embryonic mouse telencephalon. Neural Dev. 2009;4:5.

33. Long JE, Garel S, Depew MJ, Tobet S, Rubenstein JL. DLX5 regulates development of peripheral and central components of the olfactory system. J Neurosci. 2003;23:568-78.

34. Wang B, Long JE, Flandin P, Pla R, Waclaw RR, Campbell K, Rubenstein JL. Loss of Gsx1 and Gsx2 function rescues distinct phenotypes in Dlx1/2 mutants. J Comp Neurol. 2013;521:1561-84.

35. Dessaud E, Yang LL, Hill K, Cox B, Ulloa F, Ribeiro A, Mynett A, Novitch BG, Briscoe J. Interpretation of the sonic hedgehog morphogen gradient by a temporal adaption mechanism. Nature. 2007:450:717-20.

36. Qin S, Madhavan M, Waclaw RR, Nakafuku M, Campbell K. Characterization of a new Gsx2-cre line in the developing mouse telencephalon. Genesis. 2016;54:542-9.

37. Madisen L, Zwingman TA, Sunkin SM, Oh SW, Zariwala HA, Gu H, Ng LL, Palmiter RD, Hawrylycz MJ, Jones AR, Lein ES, Zeng $\mathrm{H}$. A robust and highthroughput Cre reporting and characterization system for the whole mouse brain. Nat Neurosci. 2010;13:133-40.

38. Quinn ME, Haaning A, Ware SM. Preaxial polydactyly caused by Gli3 haploinsufficiency is rescued by Zic3 loss of function in mice. Hum Mol Genet. 2012;21:1888-96.

39. Li H, Zeitler PS, Valerius MT, Small K, Potter SS. Gsh-1, an orphan Hox gene, is required for normal pituitary development. EMBO J. 1996;15:714-24.

40. Toresson H, Potter SS, Campbell K. Genetic control of dorsal-ventral identity in the telencephalon: opposing roles for Pax6 and Gsh2. Development. 2000;127:4361-71.

41. Valerius MT, Li H, Stock JL, Weinstein M, Kaur S, Singh G, Potter SS. Gsh-1: a novel murine homeobox gene expressed in the central nervous system. Dev Dyn. 1995;203:337-51.

42. Chenn A, Walsh CA. Regulation of cerebral cortical size by control of cell cycle exit in neural precursors. Science. 2002;297:365-9.

43. Toresson H, Mata de Urquiza A, Fagerström C, Perlmann T, Campbell K. Retinoids are produced by glia in the lateral ganglionic eminence and regulate striatal neuron differentiation. Development. 1999;126:1317-26.

44. Inoue T, Ota M, Ogawa M, Mikoshiba K, Aruga J. Zic1 and Zic3 regulate medial forebrain development through expansion of neuronal progenitors. J Neurosci. 2007:27:5461-73.

45. Rubin AN, Alfonsi F, Humphreys MP, Choi CK, Rocha SF, Kessaris N. The germinal zones of the basal ganglia but not the septum generate GABAergic interneurons for the cortex. J Neurosci. 2010;30:12050-62.

46. Hoch RV, Clarke JA, Rubenstein JL. Fgf signaling controls the telencephalic distribution of Fgf-expressing progenitors generated in the rostral patterning center. Neural Dev. 2015;10:8.

47. Lyons GE, Micales BK, Schwarz J, Martin JF, Olson EN. Expression of mef2 genes in the mouse central nervous system suggests a role in neuronal maturation. J Neurosci. 1995:15:5727-38.

48. López-Juárez A, Howard J, Ullom K, Howard L, Grande A, Pardo A, Waclaw R, Sun YY, Yang D, Kuan CY, Campbell K, Nakafuku M. Gsx2 controls regionspecific activation of neural stem cells and injury-induced neurogenesis in the adult subventricular zone. Genes Dev. 2013;27:1272-87.

49. Delgado RN, Lim DA. Embryonic Nkx2.1-expressing neural precursor cells contribute to the regional heterogeneity of adult V-SVZ neural stem cells. Dev Biol. 2015;407:265-74.

50. Pei Z, Wang B, Chen G, Nagao M, Nakafuku M, Campbell K. Homeobox genes GsX1 and Gsx2 differentially regulate telencephalic progenitor maturation. Proc Natl Acad Sci U S A. 2011;108:1675-80.

51. Waclaw RR, Ehrman LA, Pierani A, Campbell K. Developmental origin of the neuronal subtypes that comprise the amygdalar fear circuit in the mouse. J Neurosci. 2010;30:6944-53.

52. Szucsik JC, Witte DP, Li H, Pixley SK, Small KM, Potter SS. Altered forebrain and hindbrain development in mice mutant for the Gsh-2 homeobox gene. Dev Biol. 1997;191:230-42.

53. Lu QR, Yuk D, Alberta JA, Zhu Z, Pawlitzky I, Chan J, McMahon AP, Stiles CD, Rowitch DH. Sonic hedgehog-regulated oligodendrocyte lineage genes encoding bHLH proteins in the mammalian central nervous system. Neuron. 2000;25:317-29.

54. Takebayashi H, Yoshida S, Sugimori M, Kosako H, Kominami R, Nakafuku M, Nabeshima Y. Dynamic expression of basic helix-loop-helix Olig family members: implication of Olig2 in neuron and oligodendrocyte differentiation and identification of a new member, Olig3. Mech Dev. 2000; 99:143-8.

55. Nery S, Wichterle H, Fishell G. Sonic hedgehog contributes to oligodendrocyte specification in the mammalian forebrain. Development. 2001;128:527-40.

56. Ono K, Takebayashi H, Ikeda K, Furusho M, Nishizawa T, Watanabe K, Ikenaka K. Regional- and temporal-dependent changes in the differentiation of Olig2 progenitors in the forebrain, and the impact on astrocyte development in the dorsal pallium. Dev Biol. 2008;320:456-68.

57. Chapman H, Waclaw RR, Pei Z, Nakafuku M, Campbell K. The homeobox gene Gsx2 controls the timing of oligodendroglial fate specification in mouse lateral ganglionic eminence progenitors. Development. 2013;140: 2289-98.

58. Bayer SA. 3H-thymidine-radiographic studies of neurogenesis in the rat olfactory bulb. Exp Brain Res. 1983;50:329-40.

59. Fujiwara N, Cave JW. Partial conservation between mice and humans in olfactory bulb interneuron transcription factor codes. Front Neurosci. 2016; 10:337.

\section{Submit your next manuscript to BioMed Central and we will help you at every step:}

- We accept pre-submission inquiries

- Our selector tool helps you to find the most relevant journal

- We provide round the clock customer support

- Convenient online submission

- Thorough peer review

- Inclusion in PubMed and all major indexing services

- Maximum visibility for your research

Submit your manuscript at www.biomedcentral.com/submit
Biomed Central 